\title{
UJI KANDUNGAN LOGAM BERAT TIMBAL (Pb) DI PERAIRAN WILAYAH PESISIR PAREPARE
}

\section{Leading Heavy Metal Content Test (Pb) of Coastal Area Waters in Parepare}

\author{
Ramlia $^{1}$, Rahmi Amir ${ }^{2}$, Abidin Djalla ${ }^{3}$ \\ ${ }^{1}$ Mahasiswa Fakultas Ilmu Kesehatan Universitas Muhammadiyah Parepare \\ ${ }^{2}$ Dosen Program Studi Kesehatan Masyarakat Universitas Muhammadiyah Parepare \\ ${ }^{3}$ Dosen Program Studi Kesehatan Masyarakat Universitas Muhammadiyah Parepare \\ (ramliakesling14@gmail.com)
}

\begin{abstract}
ABSTRAK
Perairan Parepare merupakan kawasan andalan yang sejauh ini berperan dan berfungsi sebagai pusat pelayanan jasa pelabuhan. Aktivitas pelabuhan dapat menjadi salah satu sumber pencemaran logam berat. Adanya logam berat di perairan sangat berbahaya baik secara langsung terhadap kehidupan organisme, ataupun terhadap kesehatan manusia. Salah satu pencemaran logam berat yang berbahaya bagi kesehatan manusia adalah timbal, karena bersifat toksis yang dapat menimbulkan efek kesehatan seperti gangguan sistem reproduksi, sistem syaraf, jantung dan ginjal. Penelitian ini bertujuan untuk menganalisis pencemaran logam berat timbal di perairan wilayah pesisir Parepare. Metode yang digunakan dalam penelitian ini adalah metode deskriptif dengan pendekatan Cross Sectional. Peneliti mengidentifikasi melalui observasional dan dengan melakukan uji laboraturium, sampel dalam penelitian ini sebanyak 5 lokasi . Data dianalisis secara deskriptif dengan membandingkan dengan standar baku mutu air laut dalam bentuk tabel atau grafik. Hasil penelitian menunjukkan terjadi pencemaran logam berat timbal di perairan wilayah pesisir Parepare pada 5 lokasi pengambilan sampel, dimana pada Lumpue di peroleh nilai $(0,66 \mathrm{mg} / \mathrm{L})$, Sumpang minangae $(0,34 \mathrm{mg} / \mathrm{L})$, Mattirotasi $(0,70 \mathrm{mg} / \mathrm{L})$, pelabuhan Nusantara $(0,56 \mathrm{mg} / \mathrm{L})$, dan Lakessi diperoleh nilai $(0,58 \mathrm{mg} / \mathrm{L})$. Hal ini telah melebihi standar baku mutu air laut, sehingga pemerintah perlu melakukan pengawasan terhadap kebersihan pesisir secara berkala dan melakukan penanaman vegetasi magrove.
\end{abstract}

\section{Kata Kunci : Logam berat, Timbal (Pb), Pesisir}

\section{ABSTRACT}

Water in parepare is a mainstay area that has so far played a role as a port service center. Port activity can be a source of heavy metal pollution. The existence of heavy metals in waters was very dangerous both directly to the life of the organism, or to human health. One of the heavy metal pollution that was harmful to human health was lead, because it was toxic which can cause health effects such as disorders of the reproductive system, nervous system, heart and kidneys. The purposebof this study was to analyze the pollution of lead heavy metals in the water of the coastal area of Parepare.The method used in this study was a descriptive method with a Cross Sectional approach. Researcher identified through observational and by conducting laboratory tests, the samples in this study were 5 locations. Data were analyzed descriptively by comparing sea water quality standards in the form of tables or graphs. The results showed that there was heavy metal contamination of lead in the waters of the Parepare coastal area at 5 sampling locations, where the Lumpue values were obtained $(0.66 \mathrm{mg} / \mathrm{L})$, Minangke in Minutes $(0.34 \mathrm{mg} / \mathrm{L})$, Mattirotation $(0.70$ $\mathrm{mg} \mathrm{mg} / \mathrm{L})$, Nusantara port $(0.56 \mathrm{mg} / \mathrm{L})$, and Lakessi obtained a value $(0.58 \mathrm{mg} / \mathrm{L})$. This has exceeded the sea water quality standard, so the government should monitor coastal cleanliness on a regular basis and plant magrove vegetation.

Keyword : Heavy metals, Lead (Pb), Coastal 


\section{PENDAHULUAN}

Indonesia memiliki wilayah perairan yang lebih luas dibanding daratannya, diperkirakan dua per tiga wilayah Indonesia adalah perairan laut yang terdiri dari perairan pesisir (continental shelf), teluk, selat, dan laut lepas. Masalah lingkungan pesisir merupakan masalah nasional yang menjadi keprihatinan dan tanggung jawab semua pihak mengingat besarnya potensi yang dapat dimanfaatkan untuk pembangunan demi kelangsungan hidup masyarakat. Sekitar $60 \%$ dari penduduk Indonesia hidup dan bermukim di wilayah pesisir. Hal ini dikarenakan selain kondisi geografi Indonesia yang dibentuk oleh gugusan pulau-pulau besar dan kecil, wilayah pesisir juga merupakan wilayah yang sangat potensial baik sebagai sumber pangan, media jasa perhubungan, pertahanan, juga wilayah pesisir memilki nilai estetika yang sangat tinggi bagi objek parawisata maupun sektor jasa lainnya. Oleh sebab itu wilayah pesisir merupakan salah satu kemampuan masyarakat Indonesia dalam pemenuhan kebutuhan hidup dimasa depan. ${ }^{1}$

Sulawesi Selatan dalam hal ini khususnya perairan laut Parepare, memegang peran penting dalam menunjang kebutuhan hidup dari sebagian masyarakatnya, yang paling umum adalah berupa kebutuhan ikan yang dapat meningkatkan pendapatan bagi sebagian masyarakat terutama nelayan. Selain itu terdapat 3 (tiga) pelabuhan yang digunakan sebagai pelabuhan yang menghubungkan antar pulau, diantaranya adalah pelabuhan Nusantara, Cappa Ujung, dan Lontange. Secara geografis perairan Teluk Parepare dengan luas 2.778 Ha dan panjang pesisir $\pm 34 \mathrm{~km}^{2}$, diukur mulai dari pesisir Kota Parepare yang berbatasan dengan Kabupaten Barru, sampai dengan wilayah pesisir Ujung Lero, Kecamatan Suppa Kabupaten Pinrang. Kota Parepare terletak antara $3^{\circ} 57^{\prime} 39^{\prime \prime}-4^{\circ} 04^{\prime} 49^{\prime \prime}$ Lintang Selatan dan $119^{\circ} 36^{\prime} 24^{\prime \prime}$ - $119^{\circ} 43^{\prime} 40^{\prime \prime}$ Bujur Timur, berbatasan dengan Kabupaten Pinrang di sebelah Utara, Kabupaten Sidrap di sebelah Timur, Kabupaten Barru di sebelah Selatan, dan Selat Makassar di sebelah Barat. Luas wilayah Kota Parepare tercatat $\pm 99,33 \mathrm{~km}^{2}$, meliputi 4 (empat) kecamatan (Kecamatan Bacukiki, Bacukiki Barat, Ujung, dan Soreang) dan 22 (dua puluh dua) kelurahan (Kota Parepare Dalam Angka 2016). ${ }^{2}$

Perairan Parepare merupakan kawasan andalan Provinsi Sulawesi Selatan yang sejauh ini berperan dan berfungsi sebagai pusat pelayanan jasa pelabuhan, bongkar muat barang, pendistribusian minyak, sistem pemukiman serta pengembangan sektor pangan. Aktivitas pelabuhan dapat menjadi salah satu sumber pencemaran logam berat di perairan di sekitarnya. Umumnya bahan bakar minyak mendapat zat tambahan tetraethyl (zat aditif) yang mengandung timbal $(\mathrm{Pb})$. Selain itu aktivitas manusia yang terjadi di daratan seperti buangan limbah rumah tangga, limbah pertanian, limbah perkotaan, dapat memberikan peluang masuknya logam-logam berat di perairan pesisir. ${ }^{3}$ 
Penurunan kualitas air diakibatkan oleh adanya zat pencemar, baik berupa komponenkomponen organik maupun anorganik. Komponen-komponen anorganik diantaranya adalah logam berat yang berbahaya. Beberapa logam berat yang berbahaya dan sering mencemari lingkungan terutama adalah merkuri $(\mathrm{Hg})$, timbal $(\mathrm{Pb})$, arsen (As), tembaga $(\mathrm{Cu})$, kadmium $(\mathrm{Cd})$, khoromium $(\mathrm{Cr})$, dan Nikel (Ni). Logam-logam berat tersebut diketahui dapat mengumpul di dalam tubuh organisme, dan tetap tinggal dalam jangka waktu lama sebagai racun yang terakumulasi. $^{4}$

Adanya logam berat di perairan, sangat berbahaya, baik secara langsung terhadap kehidupan organisme, ataupun terhadap kesehatan manusia. Hal ini berkaitan dengan sifat-sifat logam berat yaitu sulit terurai, sehingga mudah terakumulasi dalam lingkungan perairan. Logam berat ini dapat menimbulkan efek kesehatan bagi manusia tergantung pada bagian mana logam berat tersebut terikat dalam tubuh. Daya racun yang dimiliki akan bekerja sebagai penghalang kerja enzim, sehingga proses metabolisme tubuh terputus. Jalur masuknya melalui kulit, pernafasan, dan pencernaan. Masing-masing logam berat tersebut memiliki dampak negatif terhadap manusia jika dikonsumsi dalam jumlah yang besar dalam waktu yang lama. ${ }^{5}$

Hasil penelitian (Usman, 2013), logam $\mathrm{Pb}$ dengan konsentrasi tinggi ditemukan di perairan pelabuhan Parepare sebesar 0,038 $\mathrm{mg} / \mathrm{L}$. Sumber pencemaran $\mathrm{Pb}$ dapat berupa tumpahan-tumpahan minyak yang terjadi di sekitar pelabuhan apabila ada aktivitas bongkar muat minyak ke darat. ${ }^{6}$ Dengan melihat kondisi kota Parepare dari berbagai aktivitas di perairannya, sehingga menjadi alasan peneliti untuk melakukan penelitian tentang “ Uji Kandungan Logam Berat Timbal $(\mathrm{Pb})$ di Perairan Wilayah Pesisir Parepare."

Tujuan dari penelitian ini adalah untuk menganalisis kandugan logam berat timbal $(\mathrm{Pb})$ di perairan wilayah pesisir Parepare.

\section{BAHAN DAN METODE}

Penelitian yang dilakukan adalah penelitian observasional menggunakan metode deskriptif dengan desain cross sectional. Pengujian kandungan timbal $(\mathrm{Pb})$ dilakukan di UPTD Laboratorium Dinas Lingkungan Hidup Kota Parepare. Sementara untuk waktu penelitian yaitu pada bulan Mei sampai bulan Juni 2018.Instrumen penelitian ini menggunakan lembar observasi dan alat laboraturium yaitu spectro direct. Populasi dalam penelitian ini adalah seluruh titik pantai pesisir Parepare dengan panjang 34 $\mathrm{km}^{2}$, diukur mulai dari pesisir Parepare yang berbatasan dengan Kabupaten Barru, sampai dengan wilayah pesisir Ujung Lero, Kecematan Suppa Kabupaten Pinrang. Adapun Sampel dalam penelitian ini adalah air laut yang diambil pada 5 lokasi pengambilan sampel yaitu : Lumpue, Sumpang Minangae, Mattirotasi, Pelabuhan Nusantara,dan Lakessi. 
Pengambilan sampel air laut dilakukan dengan metode purposive sampling. Sampel diambil hanya 1 kali yaitu pada sore hari, Besar sampel yang diambil pada masingmasing titik sebanyak $\pm 1000 \mathrm{ml}$. Data hasil pengukuran konsentrasi Timbal $(\mathrm{Pb})$ air laut dari laboraturium selanjutnya dianalisis secara diskriptif. Pengolahan dan analisis data dilakukan dengan membandingkan hasil analisis dengan baku mutu air laut apakah memenuhi syarat atau tidak memenuhi syarat berdasarkan Peraturan Gubernur Sulawesi Selatan Nomor 69 Tahun 2010 Tentang Baku Mutu dan Kriteria Kerusakan Lingkungan Hidup dimana nilai ambang batas kadar timbal adalah untuk biota laut $0,008 \mathrm{mg} / \mathrm{L}$, wisata bahari adalah $0,005 \mathrm{mg} / \mathrm{L}$, dan untuk perairan pelabuhan $0,05 \mathrm{mg} / \mathrm{L}$ kemudian di analisis dalam bentuk tabel atau grafik.

\section{HASIL}

Distribusi hasil pengujian timbal $(\mathrm{Pb})$ pada Tabel 1 menunjukkan 5 lokasi tempat pengambilan sampel. Pada lokasi pertama di daerah Lumpue diperoleh kadar timbal sebesar 0,66 mg/L, lokasi kedua di daerah Sumpang Minangae sebesar 0,34 mg/L, lokasi yang ketiga yaitu di daerah Mattirotasi sebesar 0,70 $\mathrm{mg} / \mathrm{L}$, pada lokasi keempat di daerah pelabuhan Nusantara kadar timbalnya sebesar 0,56 mg/L, dan di lokasi kelima di daerah Lakessi sebesar $0,58 \mathrm{mg} / \mathrm{L}$,sehingga secara umum dari hasil pengujian kadar timbal di perairan wilayah pesisir Parepare telah melebihi standar baku mutu air laut berdasarkan Keputusan Menteri Negara
Lingkungan Hidup Nomor 51 Tahun 2004 dimana $0,008 \mathrm{mg} / \mathrm{L}$ untuk biota laut, 0,05 $\mathrm{mg} / \mathrm{L}$ untuk perairan pelabuhan, dan 0,005 untuk wisata bahari.

Konsentrasi perbandingan hasil uji timbal pada Grafik 1 dengan standar baku mutu yang sesuai dan masih berlaku, diperoleh standar baku mutu air laut berdasarkan Peraturan Gubernur Sulawesi Selatan Nomor 69 Tahun 2010 Tentang Baku Mutu dan Kriteria Kerusakan Lingkungan Hidup. Konsentrasi kadar timbal tertinggi pada lokasi 3 yaitu di daerah Mattirotasi dengan nilai $(0,70$ $\mathrm{mg} / \mathrm{L})$. Sedangkan, konsentrasi kadar timbal terendah pada lokasi 2 yaitu di daerah Sumpang minangae dengan nilai $(0,34 \mathrm{mg} / \mathrm{L})$.

Distribusi hasil pengujian pada Tabel 2 diperoleh selisih pengujian logam berat timbal dengan standar baku mutu perairan pelabuhan dengan nilai $0,05 \mathrm{mg} / \mathrm{L}$. Pada lokasi Lumpue terjadi selisih kadar timbal 0,61 dengan kenaikan presentasi $86 \%$, di lokasi Sumpang Minangae terjadi selisih kadar timbal 0,29 dengan kenaikan presentase $74 \%$, lokasi Mattirotasi terjadi selisih kadar timbal 0,65 dengan kenaikan presentase 87\%, di lokasi Pelabuhan Nusantara terjadi selisih kadar timbal dengan kenaikan presentase 84\%, dan di lokasi Lakessi terjadi selisih kadar timbal 0,53 dengan kenaikan presentase $84 \%$.

Berdasarkan hasil analisis pada Tabel 2 menunjukkan persentase kenaikan jumlah timbal yang tertinggi yaitu pada daerah Mattirotasi dengan kenaikan $86 \%$, sedangkan 
jumlah yang terendah didapatkan di daerah Sumpang Minangae dengan kenaikan $74 \%$. Pada lokasi Sumpang Minangae dan Lakessi di dapatkan selisih berpandingan kenaikan jumlah timbal sebesar 10\% sedangkan kita ketahui bahwa karakteristik wilayah Lakessi dan Sumpang Minangae sama, dimana merupakan wilayah pasar. Pada lokasi Lumpue jika di bandingkan dengan Pelabuhan Nusantara,kenaikan jumlah presentase timbal di Lakessi lebih tinggi di bandingkan dengan Pelabuhan Nusantara.

\section{PEMBAHASAN}

Sifat logam-logam berat yang tidak dapat terurai dan mudah diabsorpsi oleh biota laut dan terakumulasi dalam tubuh, menyebabkan pencemaran. Selain menyebabkan pencemaran ekosistem, unsur logam berat secara tidak langsung juga merusak perikanan dan kesehatan manusia. Salah satu unsur logam berat yang dapat mengakibatkan keracunan pada makhluk hidup adalah Timbal $(\mathrm{Pb})$. Timbal dan persenyawaannya dapat berada di dalam badan perairan secara alamiah dan sebagai dampak dari aktifitas manusia. Keberadaan logam berat timbal yang menumpuk pada air dan sedimen akan masuk ke dalam kehidupan organisme di dalamnya, logam berat pada konsentrasi tertentu akan terakumulasi ke dalam air, biota, serta sedimen pada perairan tersebut, dan dapat menimbulkan efek toksik terhadap organisme di dalamnya. ${ }^{7}$
Distribusi hasil pengujian pada Tabel 1 menunjukkan dimana terdapat 5 lokasi tempat pengambilan sampel. Pada lokasi pertama di daerah Lumpue diperoleh kadar timbal sebesar 0,66 mg/L, lokasi kedua di daerah Sumpang Minangae sebesar $0,34 \mathrm{mg} / \mathrm{L}$, lokasi yang ketiga yaitu di daerah Mattirotasi sebesar 0,70 $\mathrm{mg} / \mathrm{L}$, pada lokasi keempat di daerah Pelabuhan Nusantara kadar timbalnya sebesar 0,56 $\mathrm{mg} / \mathrm{L}$, dan di lokasi kelima di daerah Lakessi sebesar $0,58 \mathrm{mg} / \mathrm{L}$,sehingga secara umum dari hasil pengujian kadar timbal di perairan wilayah pesisir Parepare telah melebihi standar baku mutu air laut berdasarkan Peraturan Gubernur Sulawesi Selatan Nomor 69 Tahun 2010 Tentang Baku Mutu dan Kriteria Kerusakan Lingkungan Hidup dimana $0,008 \mathrm{mg} / \mathrm{L}$ untuk biota laut, 0,05 $\mathrm{mg} / \mathrm{L}$ untuk perairan pelabuhan, dan 0,005 untuk wisata bahari.

Berdasarkan hasil perbandingan konsentrasi timbal pada Grafik 1 diperoleh nilai kadar logam berat timbal di perairan Parepare dimana yang tertinggi yaitu di daerah Mattirotasi dengan nilai $(0,70)$. Hal ini dikarenakan adanya pipa saluran buangan perkotaan berupa limbah domestik dan limbah rumah tangga yang di buang kelaut dekat dengan titik lokasi pengambilan sampel penelitian, selain itu tingginya kandungan $\mathrm{Pb}$ di perairan pesisir Parepare disebabkan karena aktivitas masyarakat yang membuang limbahnya baik itu limbah rumah tangga maupun limbah domestik sehingga diduga terjadi pengelupasan lapisan-lapisan alat 
masak seperti panci, pembuangan baterai dibadan perairan, dan dari pengelupasan cat pipa-pipa serta dinding yang digunakan oleh proyek pengairan dan masyarakat.

Aktivitas yang berpotensi mencemari pesisir dapat berasal dari daratan maupun lautan seperti limbah-limbah penduduk sekitar, aktivitas kapal-kapal yang berada di pelabuhan, aktivitas kapal nelayan, kapal pembawa minyak, pembuangan sampah penduduk, pipa-pipa industri yang berada di pesisir, dan aktivitas wisata. Salah satu bahan pencemar yang dapat mengancam kehidupan di wilayah pesisir dan lautan adalah logam berat (heavy metal). ${ }^{8}$ Dari hasil aktivitas tersebut dapat menghasilkan zat pencemar masuk kedalam lingkungan perairan melalui aliran air, pengendapan, dan jatuhan debu yang mengandung logam. ${ }^{9}$

Hasil perbandingan kadar timbal pada Grafik 1 diperoleh nilai kadar logam berat timbal yang terendah yaitu pada lokasi Sumpang Minangae, hal ini berdasarkan observasi dilihat banyaknya limbah organik yang menumpuk pada pinggiran pantai sekitar pasar sumpang minangae. Adanya sampah organik dipesisir pantai Sumpang Minangae dapat menjadi bahan biosorpsi kadar logam berat disekitarnya, karena bahan-bahan organik tersebut mampu mengikat $\mathrm{Pb}$ yang ada di air.

Salah satu tanaman yang memiliki kemampuan menyerap logam berat $\mathrm{Pb}$ adalah tanaman mangrove, karena mampu menganggulangi materi toksik diantaranya dengan melemahkan efek racun melalui pengenceran (dilusi), yaitu dengan menyimpan banyak air untuk mengencerkan konsentrasi logam berat dalam jaringan tubuhnya sehingga mengurangi toksitas logam tersebut. ${ }^{10}$

Berdasarkan distribusi hasil pengujian timbal pada Tabel 2 di peroleh bahwa antara lokasi Sumpang Minangae dengan lakessi di dapatkan selisih berpandingan kenaikan jumlah timbal sebesar $10 \%$ sedangkan kita ketahui bahwa karakteristik wilayah Lakessi dan Sumpang Minangae sama, dimana merupakan wilayah pasar. Hal ini dikarenakan pada wilayah Lakessi sekitar pasar terdapat kapal Dermaga pertamina. Dimana kita ketahui sumber utama pencemaran laut adalah berasal dari tumpahan minyak baik dari proses kapal, pengeboran lepas pantai maupun kecelakaan akibat kapal. Akibat dari tumpahan minyak ini akan sangat cepat dirasakan oleh masyarakat sekitar pantai dan sangat signifikan merusak makhluk hidup yang ada di laut.

Berdasarkan hasil pada Grafik 1 menunjukkan bahwa pada lokasi Lumpue dengan Pelabuhan Nusantara di peroleh perbandingan jumlah kenaikan presentase timbal dimana di Lakessi lebih tinggi di bandingkan dengan Pelabuhan Nusantara. Hal ini di karenan parairan di Lumpue lebih dangkal sementara di perairan pelabuhan lebih dalam. Menurut (Darmono, 2001) kehidupan laut dalam lebih sedikit terpengaruh dari pada laut dangkal. Selain itu 
air tawar biasanya mengandung material anorganik dan organik yang mengambang lebih banyak dari laut. Material tersebut mempunyai kemampuan untuk mengabsorbsi logam,sehingga pencemaran logam pada air tawar lebih mudah terjadi. ${ }^{11}$

Penelitian ini jika bandingkan dengan penelitian serupa yang dilakukan di perairan pelabuhan Parepare oleh (Usman, 2013), logam $\mathrm{Pb}$ dengan konsentrasi yaitu sebesar 0,038 $\mathrm{mg} / \mathrm{L}$,ini lebih rendah dibandingkan hasil penelitian pada tabel 1 di daerah pelabuhan Nusantara dimana di peroleh nilai $0,56 \mathrm{mg} / \mathrm{L}$. Sumber pencemaran $\mathrm{Pb}$ dapat berupa tumpahan-tumpahan minyak ke darat. Selain kegiatan bongkar muat, pencemaran logam $\mathrm{Pb}$ juga disebabkan oleh adanya kapal yang melewati kawasan industri tersebut, sehingga kemungkinan ceceran minyak juga dapat terjadi. ${ }^{6}$

Timbal mempunyai arti penting dalam dunia kesehatan bukan karena penggunaan terapinya, melainkan lebih disebabkan karena sifat toksisnya. Absorpsi timbal di dalam tubuh sangat lambat, sehingga terjadi akumulasi dan menjadi dasar keracunan yang progresif. Keracunan timbal ini menyebabkan kadar timbal yang tinggi dalam aorta, hati, ginjal, pankreas, paru-paru, tulang, limpa, testis, jantung dan otak. ${ }^{5}$

Ketika $\mathrm{Pb}$ masuk ke dalam tubuh biota laut,kemudian biota laut masuk ke dalam sistem rantai makanan sehingga sampai ke tubuh manusia dan terakumulatif, maka dapat dibayangkan akibat fatal yang dapat terjadi pada manusia. Ibu yang tubuhnya telah terkontaminasi $\mathrm{Pb}$ akan melahirkan anak yang akan mengalami gangguan pada fase awal pertumbuhan fisik dan mental dan kemudian berakibat pada fungsi kecerdasan. Sedangkan pada orang dewasa, $\mathrm{Pb}$ dapat terakumulasi pada gigi, gusi, tulang, dan anemia yang ditandai dengan gejala pucat, sakit, serta kelumpuhan. Selain itu juga dapat mengakibatkan kerusakan fungsi otak dan kegagalan fungsi ginjal. ${ }^{12}$

\section{KESIMPULAN DAN SARAN}

Berdasarkan hasil penelitian yang dilakukan di perairan wilayah pesisir Parepare yang dianalisis oleh instrumen spectro direct dapat di simpulkan bahwa terjadi pencemaran logam berat timbal di perairan pesisir Parepare di lima titik lokasi pengambilan sampel yakni Lumpue (0,66 mg/L), Sumpang Minangae (0,34 $\mathrm{mg} / \mathrm{L})$, Mattirotasi $(0,70 \mathrm{mg} / \mathrm{L})$, Pelabuhan Nusantara $(0,56 \mathrm{mg} / \mathrm{L})$, dan Lakessi $(0,58$ $\mathrm{mg} / \mathrm{L})$. Nilai ini menunjukkan bahwa kadar timbal pada lokasi tersebut telah melebihi nilai ambang batas standar baku mutu air laut berdasarkan Peraturan Gubernur Sulawesi Selatan Nomor 69 Tahun 2010 Tentang Baku Mutu dan Kriteria Kerusakan Lingkungan Hidup, hal ini tentunya sangat membahayakan bagi kehidupan biota laut yang juga akan berdampak pada kesehatan manusia. Oleh karena itu di sarankan bagi instansi yang terkait perlu melakukan pencegahan dan pengendalian 
terhadap pencemaran logam berat dan juga melestarikan perairan pesisir Parepare. masyarakat agar kiranya tetap menjaga dan

\section{DAFTAR PUSTAKA}

1. Dahuri R. 2004. Paradigma Baru Pembangunan Indonesia Berbasis Kelautan. Naskah Orasi Ilmiah Pengukuhan Guru Besar Tetap Ilmu Pengelolaan Sumberdaya Pesisir dan Lautan. Institut Pertanian Bogor.

2. Kota Parepare Dalam Angka 2016. http://www.pareparekota.go.id/kominfo/profil kota/geografis\#geografi [31 Agustus 2018].

3. Chandra B. 2007.Pengantar Kesehatan Lingkungan. EGC. Jakarta. Penerbit : Buku Kedokteran.

4. Palar H. 2008. Pencemaran dan Toksikologi Logam Berat. Penerbit Rineka Cipta. Jakarta.

5. Sudarmaji.2006.Toksikologi Logam Berat B3 dan Dampaknya Terhadap Kesehatan. Jurnal Kesehatan Lingkungan, VOL 2, NO.2 Januari 2006 :129-142,FKM Universitas Airlangga.http://www.journal.unair.ac.id// filer PDF/Kesling-2-2-03.pdf. [diakses tanggal 20 Maret 2018].

6. Usman S dkk. 2013. Distribusi Kuantitatif Logam Berat Pb dalam Air, Sedimen, dan Ikan Merah(Lutjanus erythropterus) di Sekitar Pelabuhan Parepare. Marina Chimica Acta, Vol.14 (2), Hal. 49-55 http://Journal.Unhas.ac.id/ index/Php/mca/article/view/1189. [diaksestanggal 22 maret 2018].

7. Sembel DT. 2015. Toksikologi Lingkungan Dampak Pencemaran dari Berbagai Bahan Kimia dalam Kehidupan Sehari - hari. Yogyakarta: Penerbit Andi.

8. Astuti dkk. 2016. Analisis kandungan logam berat $\mathrm{Pb}$ pada tiram Crassostrea cucullata di pesisir Krueng Raya, Aceh Besar. Jurnal Ilmiah Mahasiswa Kelautan dan Perikanan Unsyiah.1(1): 104113. http://www.Jim.Unsyah .ac.id/FKP/article/view/12 [diakses tanggal 20 Maret 2018].

9. Musriadi. 2014. Akumulasi Logam Tembaga $(\mathrm{Cu})$ dan Timbal $(\mathrm{Pb})$ pada Karang Acropora formosa dan Acropora hyacinthus di Pulau Samalona, Barrang lompo dan Bonebatang, Kota Makassar. Skripsi. http://repositori.uin. alauddin.ac.id [diakses tanggal 19 Maret 2018].

10.Supryantini E dkk. 2017. Jurnal kelautan tropis. Daya serap mangrove Rhyzophora Sp. terhadap logam berat timbal $(\mathrm{Pb})$ mangrove park, Pekalongan. Vol.20(1):16-24 https://ejournal2. Undip.ac.id. [diakses tanggal 20 Oktober 2018].

11.Darmono. 2001. Lingkungan Hidup dan Pencemaran: Hubungan Toksi- kologi dengan Senyawa Logam. Jakarta: Penerbit Universitas Indonesia.

12.Nuraini dkk. 2015.Analisis Logam Berat Dalam Air Minum Isi Ulang (AMIU) dengan menggunakan Metode Spectrofotometri Serapan Atom (SSA). Gravitasi Vol. 14 No.1(Januari-Juni 2015).https://www.Jurnal.Unrika.ac.id [diakses tanggal 19 Maret 2018]. 


\section{LAMPIRAN}

Tabel 1. Distribusi Hasil Pengujian Logam Berat Timbal di Perairan Wilayah Pesisir Parepare Tahun 2018

\begin{tabular}{lcc}
\hline \multicolumn{1}{c}{ Lokasi } & Kadar Timbal (mg/L) & Standar baku mutu \\
\hline Lumpue & 0,66 & $* 0,008 \mathrm{mg} / \mathrm{L}$ untuk biota \\
Sumpang Minangae & 0,34 & laut, $0,05 \mathrm{mg} / \mathrm{l}$ untuk \\
Mattirotasi & 0,70 & perairan pelabuhan, 0,005 \\
Pelabuhan Nusantara & 0,56 & untuk wisata bahari \\
Lakessi & 0,58 & \\
\hline
\end{tabular}

Sumber : Data Primer (2018)

Ket $\quad$ :*Peraturan Gubernur Sulawesi Selatan Nomor 69 Tahun 2010

Grafik histogram perbandingan kadar $\mathrm{Pb}$ di setiap lokasi pengambilan sampel dapat diilustrasikan pada Grafik 1.

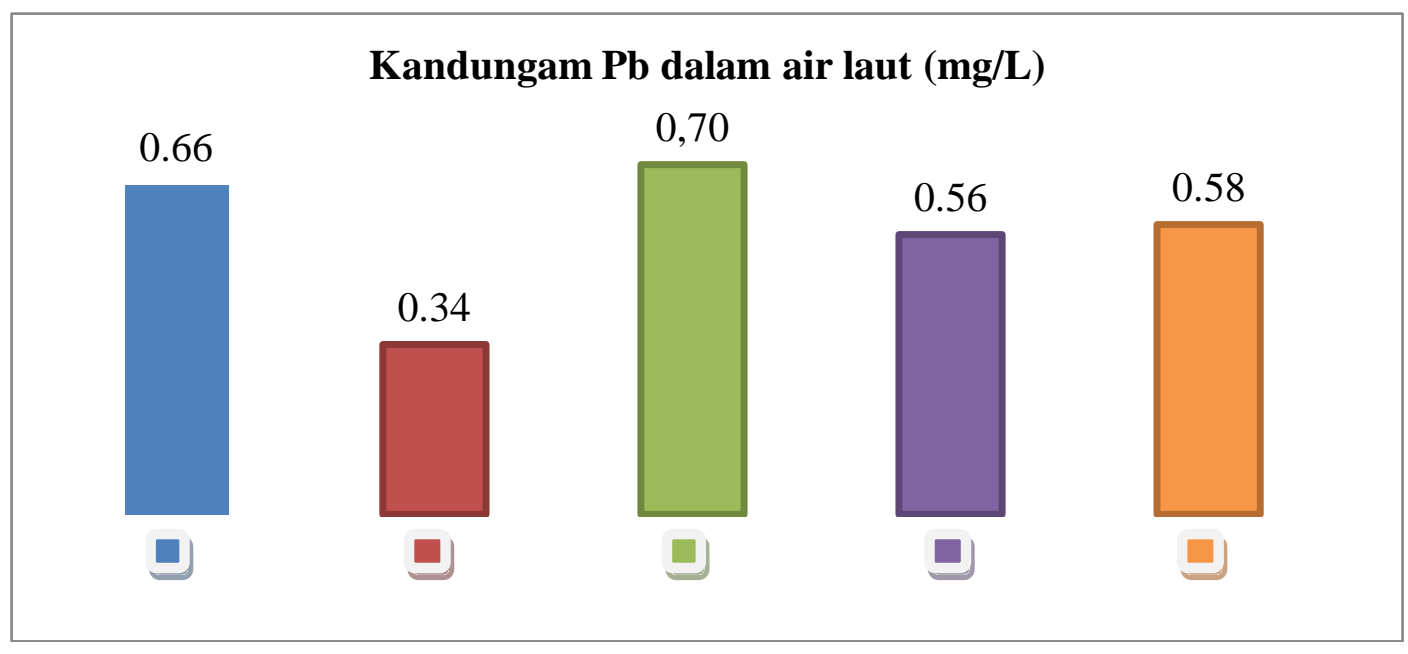

Grafik 1. Histogram kandungan logam berat $\mathrm{Pb}$ pada perairan pesisir Parepare

\section{Keterangan :}

Lumpue

Sumpang Minangae

Mattirotasi
PelabuhanNusantara

Lakessi 
Tabel 2. Distribusi selisih hasil pengujian logam berat timbal dengan standar baku mutu perairan pelabuhan dengan nilai $0,05 \mathrm{mg} / \mathrm{L}$.

\begin{tabular}{lcc}
\hline \multicolumn{1}{c}{ Lokasi } & $\begin{array}{c}\text { Selisih kadar timbal } \\
(\mathbf{p p m})\end{array}$ & $\begin{array}{c}\text { Kenaikan jumlah timbal dengan } \\
\text { standar baku mutu (\%) }\end{array}$ \\
\hline Lumpue & 0,61 & 86 \\
Sumpang minangae & 0,29 & 74 \\
Mattirotasi & 0,65 & 87 \\
Pelabuhan Nusantara & 0,51 & 84 \\
Lakessi & 0,53 & 84 \\
\hline
\end{tabular}

Sumber : Data Primer (2018) 